\title{
Dopamine and serotonin transporter genotypes moderate sensitivity to maternal expressed emotion: The case of conduct and emotional problems in Attention Deficit/Hyperactivity Disorder.
}

\author{
Edmund J. S. Sonuga-Barke ${ }^{1,2,3,{ }^{*}}$, Robert D. Oades ${ }^{4}$, Lamprini Psychogiou ${ }^{5}$, Wai \\ Chen $^{1,2}$, Barbara Franke ${ }^{6,7}$, Jan Buitelaar ${ }^{7}$, Tobias Banaschewski ${ }^{8,9}$, Richard Ebstein ${ }^{10}$, \\ Michael Gill ${ }^{11}$, Richard Anney ${ }^{11}$, Ana Miranda ${ }^{12}$, Herbert Roeyers ${ }^{3}$, Aribert \\ Rothenberger $^{8}$, Joseph Sergeant ${ }^{13}$, Hans-Christoph Steinhausen ${ }^{14}$, Margaret \\ Thompson $^{1}$, Philip Asherson ${ }^{2}$, Stephen V. Faraone ${ }^{15}$
}

\section{Journal of Child Psychology and Psychiatry, 50, 1052-1063}

This is the reformatted manuscript submitted - prior to publication in its final form at (www.springerlink.com) DOI: 10.1111/j.1469-7610.2009.02095.x

1. Developmental Brain-Behaviour Laboratory, University of Southampton, Southampton, UK.

2. Social Genetic and Developmental Psychiatry Centre, Institute of Psychiatry, University of London, UK.

3. Department of Experimental Clinical Psychology, University of Gent, Belgium.

4. University Clinic for Child and Adolescent Psychiatry, Essen, Germany.

5. Department of Psychiatry, University of Oxford, UK.

6. Department of Psychiatry, Radboud University Nijmegen Medical Centre, Nijmegen, The Netherlands.

7. Department of Human Genetics, Radboud University Nijmegen Medical Centre, Nijmegen, The Netherlands.

8. Child and Adolescent Psychiatry, University of Göttingen, Göttingen, Germany.

9. Department of Child and Adolescent Psychiatry and Psychotherapy, Central Institute of Mental Health, University of Mannheim, Mannheim, Germany.

10. Herzog Memorial Hospital, Jerusalem, Israel.

11. Department of Psychiatry, Trinity Centre for Health Sciences, St. James's Hospital, Dublin, Ireland.

12. Department of Developmental and Educational Psychology, University of Valencia, Spain.

13. Vrije Universiteit, De Boelelaan, Amsterdam, The Netherlands.

14. Department of Child and Adolescent Psychiatry, University of Zurich, Switzerland.

15. Child and Adolescent Psychiatry Research, SUNY Upstate Medical University, Syracuse, New York, USA.

* Correspondence: Email: ejb3@soton.ac.uk

\section{Financial Disclosures \& Conflicts of Interest}

Edmund J.S. Sonuga-Barke: Speaker for Shire Pharma, UCB Pharma, Medice. Consultancy currently from UCB Pharma and Shire. Current research support from Janssen Cilag. Advisory Board member Shire, UCB Pharma and Flynn Pharma. Robert Oades: support for investigator initiated study from UCB GmbH. Lamprini Psychogiou: no financial disclosures or conflicts of interest to report. Wai Chen: Lecture Fees from Janssen Cilag and Lilly; grant support from NIMH and Janssen Cilag. Barbara Franke: no financial disclosures or conflicts of interest to report. Jan Buitelaar: Jan $\mathrm{K}$ Buitelaar has been a consultant to / member of advisory board of / and/or speaker for Janssen Cilag BV, Eli Lilly, Bristol-Myer Squibb, Organon, UCB, Shire, Medice, Pfizer. Tobias Banaschewski: Prof. Banaschewski served in an advisory or consultancy role for Lilly, Medice, Novartis, Pfizer, Shire, and UCB. He received conference attendance support or was paid for public speaking by Lilly, Janssen McNeil, Medice, Novartis, and UCB. Richard Ebstein: no financial disclosures of conflicts of interest to report. Michael Gill: no financial disclosures or conflicts of interest to report. Richard Anney: no financial conflicts regarding this manuscript. Ana Miranda: No biomedical financial interest and no potential conflict of interest. Herbert Roeyers: Research grant from Lilly. Aribert Rothenberger: Advisory Board and/or Speakers Bureau of Medice, Lilly, Janssen-Cilag, Shire, UCB, Novartis, Cephalon Educational Grant from Lilly, Shire. Joseph Sergeant: Professor Sergeant is member of the advisory board of Lilly, Novartis and Shire. He has also received a research project from Lilly. Hans Christoph Steinhausen: No conflicts of interest. Margaret Thompson: Lectures fees from Eli Lilley, UCB, Janssen Cilag; Research grants from Eli Lilley, UCB, Janssen Cilag, Primary Care Trust, Mental Health Network, MHF, Dept. of Health, South West R\&D Wessex, HOPE, National Institute for Mental Health USA; Medication Trials from Eli Lilley, Janssen Cilag; Case Award to PhD Students from Eli Lilley, UCB, Janssen Cilag; Conference Sponsorship from Eli Lilley, UCB, Janssen Cilag; Advisor fees from Eli Lilly, UCB, Janssen Cilag, Flynn Pharma, Shire. Philip Asherson: Asherson has given sponsored talks for Shire, Janssen-Cilag, Eli-Lilly and UCB Pharma on treatment of ADHD in adults and has been on advisory boards for Jansen-Cilag, Shire and Pfizer regarding treatment of ADHD; all funds have been donated to the University research fund for studies of ADHD. He is the current holder of government funded projects on ADHD from the National Institute of Health Research in the UK. Stephen V. Faraone: Dr. Faraone receives research support from and consults to Shire Pharmaceutical Development. He receives grant support from Eli Lilly and the US National Institutes of Health. 


\section{ABSTRACT:}

BACKGROUND: Mothers' positive emotions expressed about their children with Attention Deficit/Hyperactivity Disorder (ADHD) are associated with a reduced likelihood of comorbid conduct problems (CP). We examined whether this association with $\mathrm{CP}$, and one with emotional problems (EMO), is moderated by variants within three genes, previously reported to be associated with $A D H D$ and to moderate the impact of environmental risks on conduct and/or emotional problems; the dopamine transporter gene (SLC6A3/DAT1), the dopamine D4 receptor gene (DRD4) and the serotonin transporter gene (SLC6A4/5HTT).

METHODS: 728 males between the ages of 5 and 17 with a DSM-IV research diagnosis of combined type ADHD were included in these analyses. Parents and teachers rated children's conduct and emotional problems. Positive maternal expressed emotion (PMEE) was coded by independent observers on comments made during a clinical assessment with the mother based on current or recent medication-free periods.

RESULTS: Sensitivity to the effects of PMEE on CP was moderated by variants of the DAT1 and $5 \mathrm{HTT}$ genes. Only children who did not carry the DAT1 10R/10R or the 5HTT I/I genotypes showed altered levels of CP when exposed to PMEE. The effect was most marked where the child with ADHD had both these genotypes. For EMO, sensitivity to PMEE was found only with those who carried the DAT1 9R/9R. There was no effect of DRD4 on CP or EMO.

CONCLUSION: The gene-environment interactions observed suggested that genetic make-up can alter the degree of sensitivity ADHD patients have to their family environment. Further research should focus on distinguishing general sensitivity genotypes from those conferring risk or protective qualities.

Keywords: ADHD, gene x environment interaction, conduct problems, emotional symptoms, expressed emotion, mothers, teachers, genetics, serotonin transports, dopamine transport

\section{INTRODUCTION:}

Attention Deficit/Hyperactivity Disorder (ADHD) frequently presents comorbid with conduct problems (CP; Biederman, 2005; Lahey, McBurnett, \& Loeber, 2000) and emotional disorders (EMO; i.e., anxiety - Tannock, 2000; depression Jensen et al., 2001). Children with comorbidity have poorer outcomes than children with ADHD alone (Hinshaw, 1992; Lynam, 1996). Multiple genetic and environmental risk factors are likely to drive the development of comorbidity in children with ADHD (Schachar \& Tannock, 1995). For instance, childhood ADHD is associated with negative parentchild relationships (Pfiffner et al., 2005) and parental attitudes and actions expressed towards/about their child have been hypothesized to play an important role in the development of comorbidity (Johnston \& Mash, 2001). The particular factors of significance may be different for CP and EMO (Vostanis et al., 1994). For $\mathrm{CP}$, levels of positive/negative emotions expressed by a parent about/towards their ADHD child appear to be important (Baker, Heller \& Henker, 2000; Daley, Sonuga-Barke \& Thompson, 2003; Psychogiou et al., 2007). Taylor et al. (1996) found that low levels of 'warmth' and high levels of 'criticism' expressed by mothers about their children with pervasive symptoms of ADHD at age 7 years, predicted the later development of comorbid $\mathrm{CP}$ at the age of 17 years; whereas there was no developmental link between $\mathrm{CP}$ in 7-year olds and the later development of ADHD by age 17 years. Conversely, high levels of parental warmth and low levels of criticism appeared to be protective for ADHD children with regard to CP. Such data is consistent with 
Patterson's (1982) model of the role of a coercive cycle of interaction between parent and child playing a key role in the development of CP in ADHD. In contrast, parental expressed hostility does not, in general, appear to predict the emergence of EMO (Stubbe et al. 1993; Vostanis et al., 1994). Over-protectiveness, insularity and discouragement (anxiety - Pfiffner \& McBurnett, 2006; Kepley \& Ostrander, 2007) and lack of monitoring and positive feedback (depression - Ostrander \& Herman, 2006) seem distinctive elements of the parenting of ADHD children with internalising problems.

A number of genetic variants are reported to moderate the effects of environmental risk of comorbidity in ADHD (Thapar et al., 2007). The current paper examined three variable number tandem repeat polymorphisms (VNTRs) within genes involved in the regulation of the dopamine and serotonin neurotransmitter systems, as potential moderators of the effects of maternal expressed emotion on the development of CP and EMO in ADHD; The dopamine transporter gene (SLC6A3/DAT1); the dopamine D4 receptor gene (DRD4) and the serotonin transporter gene (SLC6A4/5HTT-LPR). For DAT1, most studies suggest that the risk of ADHD is increased in children homozygous for the 10R (Faraone et al., 2005). However, the evidence is far from consistent. Li et al. (2006) updated this work and failed to find evidence of an association with ADHD and the 10R allele in family-based studies, although there was significant evidence of heterogeneity between studies. The most recent metaanalysis of this gene found a small but significant association with ADHD for family-based, but not case-control studies (Yang et al., 2007). The heterogeneity in findings could arise at least in part from the additive or interactive effects of multiple functional variants within DAT1 (Asherson et al., 2007; Brookes et al., 2006a, 2006b). There is also evidence for interactions between this genotype and both prenatal environmental risk factors and psychosocial adversity (Becker et al., 2008; Kahn et al., 2003; Laucht et al., 2007; Neuman et al., 2007). Furthermore some studies have implicated the 9R allele in aspects of ADHD such as cognitive impulsivity (Kim, Kim \& Cho, 2006). DAT1 has also been implicated in the aetiology of CP more generally, with inconsistencies regarding the risk genotype. Some have implicated the 9R allele rather than the 10R allele as being most significant (Lee et al., 2007; Young et al., 2002), while others have suggested that it is the heterozygous case (i.e., $9 \mathrm{R} / 10 \mathrm{R}$ ) which is at most risk. Given this pattern of results from previous studies in the current analysis we compare the three most common DAT1 genotypes; 9R/9R, 9R/10R and 10R/10R.

For DRD4, evidence of an association between ADHD and the 7R allele located within intron 3 of the gene reached genome wide significance in a comprehensive meta-analysis of available data ( $p>5 \times 10^{-8}$; Li et al., 2006). Several potential gene by environment interactions involving the DRD4 polymorphism have been reported. Maternal insensitivity was associated with preschool externalizing disorders only in children carrying the $7 \mathrm{R}$ allele (Bakermans-Kranenburg \& van IJzendoorn, 2006) and parental warmth was protective for externalizing disorders only in the absence of the 7-repeat allele, and only for African-American children (Propper et al., 2007). In keeping with this literature our main DRD4 analysis compares individuals with and without the $7 \mathrm{R}$ allele, although preliminary analyses were carried out on other common alleles.

Support for the association between ADHD and the long (1) allele of an insertion/deletion polymorphism within the promoter region of the serotonin transporter gene (5-HTT-LPR) comes from several studies (Kent et al., 2002; Li et al., 2007). Interestingly for the current analysis, the short (s) allele of this 
polymorphism (the putative protective allele for ADHD) has been reported to interact with social adversity and other environmental factors to increase the risk for behavioural problems including $\mathrm{CP}$ in a number of different studies. The s allele is associated with increased risk for depression following exposure to stressful life events (Caspi et al., 2003; Kendler et al., 2005) and social adversity (Eley et al., 2004) and in children of low socioeconomic status (Cicchetti, Rogosch \& Sturge-Apple, 2007). It has also been associated with increased rates of drug abuse in the context of dysfunctional parenting (Gerra et al., 2007). This allele is associated with aggressive $\mathrm{CP}$ in middle childhood (Haberstick, Smolen \& Hewitt, 2006; although see Sakai et al., 2007) and to interact with an adverse childhood environment to increase the risk for violent conduct in young adults (Reif et al., 2007). In contrast one study found that the presence of the 1 allele interacts with socio-economic status to increase childhood externalising problems (Nobile et al., 2007). Given the inconsistency of findings our analyses will compare the s/s, s/l and $1 / 1$ genotypes.

Polymorphisms in the Monoamine Oxidase (MAOA) gene have been suggested to moderate the effects of childhood maltreatment on the development of CP (Kim-Cohen et al., 2006) while the Catechol-O-methyl transferase (COMT) gene appears to mark a subtype of ADHD patients more likely to have CP (Caspi et al., 2008). While these are two excellent additional candidates for the sort of analysis conducted here, the relevant polymorphisms had not been genotyped for the whole IMAGE sample at the time these analyses had been carried out.

In the current study we examined the moderating role of the variants in the three selected genes on the association between maternal EE, (with specific reference to maternal warmth and criticism), and $\mathrm{CP}$ and EMO using a cross-sectional design.
Based on the available literature that identifies a role for $\mathrm{EE}$ in the developmental link from ADHD to $\mathrm{CP}$, we predicted that parental warmth and low levels of criticism would be associated with lower levels of CP, but not EMO. We did not measure factors such as intrusiveness or over-protectiveness that might be implicated in EMO in ADHD according to the literature. Our aim was to test the hypothesis that genotypic variations in our three candidate genes (DRD4, DAT1 and 5HTT-LPR) moderate the protective effect of positive maternal EE (PMEE) on the risk for $\mathrm{CP}$ but not EMO. Given the exploratory nature of these analysis and the mixed findings from previous studies we made no directional predictions with regard to specific genotypes that might promote or suppress the effects of PMEE.

The analyses reported were part of an ongoing large-scale study of the molecular genetics of ADHD; The Multi-centre ADHD Genetics (IMAGE) study. Analyses of VNTRs in the IMAGE sample supported the association between ADHD and the 10-repeat allele and a specific haplotype of DAT1 (Asherson et al., 2007), but no association with VNTRs in the 5HTT gene (Xu et al., 2008). SNP-based analyses found evidence of association between ADHD and SNPs in both DAT1 and DRD4 (Brookes et al., 2006a), as well as an empirically derived quantitative trait measures of ADHD symptoms (Lasky-Su et al., 2007). For DAT1 two independent regions of association were identified in the 3 ' and 5' ends of the gene. Further analyses looking at interactions with clinical subtypes or environmental risk measures found that neither DAT1 or DRD4 were associated with IQ (Sonuga-Barke et al., 2008a), DAT1 did not show an interaction with exposure to prenatal smoking (Altink et al., 2008) and DRD4 was not moderated by season of birth (Brookes et al., 2008). Analysis of ADHD with and without comorbid CP demonstrated that the DAT1 associations 
with ADHD were restricted to the pure ADHD group, which did not have comorbidity with CP (Zhou et al., 2008). The EE variables used in the current analysis have been employed in a secondary analysis of Genome Wide Association Scan data in which partitioning by EE allowed us to identify a number of new candidate genes for ADHD and $\mathrm{CP}$ (although none reached genome wide significance; Sounga-Barke et al., 2008b). Finally, an unpublished analysis supports a differential role for maternal and paternal $\mathrm{EE}$ in relation to $\mathrm{CP}$ and EMO (Psychogiou et al., submitted).

\section{METHODS}

\section{Participants}

The sample was drawn from the participants in the IMAGE study recruited through 12 specialist ADHD clinics in eight countries: Belgium, Germany, Netherlands, Ireland, Israel, Spain, Switzerland, and the United Kingdom; as part of the NIMH-funded International Multi-centre ADHD Genetics (IMAGE) project (Brookes et al., 2006a).

The current analysis was limited to male ADHD probands whose research assessment and diagnosis was made on the basis of a current or a recent period offmedication $(\mathrm{N}=728$; mean age 11.0 years $(\mathrm{SD}=2.8)$. Male probands $(\mathrm{N}=251)$ who were being continuously medicated at the time of study were excluded from this analysis as their assessment was based on retrospective accounts by parents which may have compromised the veracity of the EE assessment. Female probands $(\mathrm{N}=127)$ were excluded as there were insufficient in number to provide the necessary statistical power to identify anticipated interactions between genotype gender and maternal EE. Probands were of European/Caucasian ancestry and between the ages of 5 to 17 years at the time of entry into the study. Entry criteria for ADHD cases were: a clinical diagnosis of DSM-IV combinedsubtype ADHD; having one or more full siblings (although these were not included in these analyses) available for ascertainment of clinical information and DNA collection; access to one or both biological parents for DNA collection. Exclusion criteria applying to both ADHD cases included autism, epilepsy, IQ $<70$, brain disorders, and any genetic or medical disorder associated with externalizing behaviours that might mimic ADHD. The Parental Account of Children's Symptoms interview (PACS see below) was conducted with all probands. The DSM-IV combined type ADHD diagnosis was confirmed by the PACS in $94.5 \%$ of cases, while $1.8 \%$ had the predominantly inattentive subtype and $3.7 \%$ had the predominantly hyperactive/impulsive subtype. A probable comorbid mood disorder was diagnosed in $15.5 \%$ of cases and a comorbid conduct disorder in $23.6 \%$ of cases. Interviewer ratings of maternal EE warmth and criticism were available for 673 of the 728 male probands. In order to examine the effects of age, boys were divided into two groups; 11 years and below $(56.2 \%)$ and 12 years of age and above (43.8\%). Genotypic data was available for a large proportion of the original 728 probands (DAT1 $\mathrm{N}=668$; DRD4 N=684; 5HTT N=681). Parental genotypes were also available (DAT1 $\mathrm{N}=663 ;$ DRD4 $\mathrm{N}=673$; 5HTT $\mathrm{N}=675$ ). Given that the availability of data varied for different genes the numbers included varied from analysis to analysis.

The IMAGE project procedures were approved by the Ethics Committees at all data collection sites and by the Institutional Review Board at the coordinating site (SUNY Upstate). All enrolled parents provided informed consent for the participation of their families in the project.

\section{Measures}

Research diagnosis was established using the PACS interview (Taylor et al., 1991; Chen \& Taylor, 2006). This is a semi-structured interview used to collect parent-based detailed information on 
children's behaviour. It is divided into four sections: Mood Disorders, ADHD/ hyperkinetic disorder, disruptive behaviour problems and additional problems. In the ADHD/Hyperkinetic Disorder section, the interviewer asks parents to describe their child's behaviour in different settings; the interviewer then rates the severity and frequency of the behaviour according to previously defined criteria. The settings were selected to represent common unstructured (watching TV, reading or playing alone), semi-structured (meals, outings or shopping) and structured (home tasks, homework or getting ready) daily life situations. In this study, parents were asked to focus on examples of their child's behaviour during current or recent medication-free periods. The interviewers made their own coding on the basis of a formal training and written definitions of the behaviours, on a 4-point scale (0 to 3 ) of severity and frequency in the previous week and previous year. A standardized diagnostic algorithm based on the DSM-IV criteria was applied to the information from PACS and from the teacher rated ADHD subscale from Conners' Teacher Rating Scale (Conners, 2003). The algorithm included behavioural symptoms, age of onset, situational pervasiveness and clinical impairment. Previous studies have shown high inter-rater reliability for this instrument (product-moment correlations between .76 and .96 (Chen \& Taylor, 2006). In order to ensure cross-site consistency within the IMAGE project in measurement and coding of PACS, all interviewers from each site attended a 5day PACS training course in the UK. The chief investigator at each site attended an annual inter-rater reliability exercise and was responsible for reliability in their native site. A mean Kappa coefficient across all sites of 0.88 (range 0.71-1.00) and an average agreement percentage of 96.6\% (range 78.6-1.00) were obtained indicating a substantial level of inter-rater agreement (Brookes et al., 2006a).
Conduct and emotional symptoms: For the current analysis, which required data from both teachers and parents, these symptom ratings were derived using the parent- and teacher-versions of the Strengths and Difficulties Questionnaire (SDQ; Goodman, 1997). This is a brief behavioural screening questionnaire that can be completed by parents or teachers of children aged 4 to 16 . Both the $\mathrm{CP}$ and EMO scale contains 5 items, each with a 3 -point response scale, ranging from 0 (Not True) to 2 (Certainly True). Cut-offs are standardised to identify the top ten percent of children within the UK (Goodman, 1997). The scale is well validated and has good test-retest reliability $(\alpha=.85)$, with similar psychometric properties in different countries (Achenbach et al., 2008).

Parental expressed criticism and warmth: Assessment of mothers' expressed criticism and warmth was made using codings derived from the Camberwell Family Interview on the basis of parental responses over the extended period of the entire clinical assessment (i.e., > 1 hour). Warmth was assessed by the tone of voice, spontaneity, sympathy, and/or empathy toward the child. A great deal of expressed warmth ( 0 ) was coded when there was definite warmth, enthusiasm, interest in, and enjoyment of the child. Quite a lot of demonstration of warmth (1) was coded when there was definite understanding, sympathy, and concern but only limited warmth of tone. Moderate demonstration of warmth (2) was coded when there was a detached and rather clinical approach, with little or no warmth of tone, but moderate understanding, sympathy, and concern. Little warmth (3) was coded when there was only a slight amount of understanding, sympathy, or concern or enthusiasm about or interest in the child or when parents did not display any of the qualities of warmth described above. Inter-rater reliability has been satisfactory; ranging from .78 to .91 (Schachar et al., 1987). 
Criticism was assessed by statements which criticised or found fault with the child based on tone of voice and critical phases. A lot of expressed criticism (4) was coded when the parent mentioned critical comments indicating that the respondent dislikes, resents, disapproves of, or is angered or annoyed by the child's behaviour or characteristics. High criticism was also based on harsh tone of voice, even if the statement did not meet the content criteria. For a statement to be considered critical, the inflection, pitch, and/or rate of speech had to be dramatically different from the preceding and usual level of speech in the interview. The tone had to strongly indicate resentment and/or anger about the topic being discussed. Quite a lot of expressed criticism (3) was coded when there were indication that the parent did not like or approve of the child's behaviour. Some criticism (2) was coded when there were statements of dissatisfaction indicating that the parent was bothered, irritated or upset by the child's behaviour or characteristics. Very little expressed criticism (1) and no expressed criticism $(0)$ were coded when there was no evidence during the interview that the parent disapproves or dislikes child's behaviour. Inter-rater reliability has been satisfactory; ranging from .79 to .86 (Schachar et al., 1987).

DNA Extraction and Genotyping: DNA was extracted directly from blood samples or cell lines at Rutgers Cell line and DNA repository in the US. In a few cases a mouth swab sampling technique was used and the DNA extracted at the SGDP laboratories in London. For genotyping of the VNTR markers we used a standard PCR method according to previous optimized protocols for the markers used in this study. Based on previous studies of ADHD and gene $\mathrm{x}$ environment interactions our analyses focused on the following genotypes: (1) for DRD4 we compared the group with either one or two copies of the 7-repeat allele with those with no copies of the $7 R$ allele. (2) For DAT1 and 5HTT-LPR: Given the inconsistency of previous results with regard to risk for ADHD and gene $\mathrm{x}$ environment interaction we compared the three common genotypes in each case. For DAT1 we compared the 9R/9R, 9R/10R and $10 \mathrm{R} / 10 \mathrm{R}$ and for the 5HTT-LPR analyses the s/s, s/l and 1/1 variants were compared.

\section{Analytical Strategy}

Maternal warmth and criticism were negatively correlated ( $r=-.54)$. In keeping with the notion of $\mathrm{EE}$ as a composite variable encompassing both elements these two scores were combined into a single factor (positive maternal EE: PMEE) using equal weightings. For the current analysis this score was dichotomized to form a binary variable (i.e., high PMEE vs. low PMEE) using a median split in the PMEE score in order to facilitate the $\mathrm{G} \times \mathrm{E}$ analyses. A number of preliminary analyses were conducted to explore the associations between child and parent genotypes and PMEE. To test for genotype $x$ maternal PMEE interaction repeated measures ANOVAs models were run with genotype (DAT1 - 9R/9R, 9R/10R, 10R/10R; DRD4 - +7 R/-7R; 5HTT-LPR - 1l, ls, ss), and PMEE (high, low) and age (under 12 years vs. 12 years and over) as the between subject variables, and rater (parent or teacher) as the within subject variable. One set of analyses had SDQ CP, and a second, SDQ EMO as the dependent variable. We also conducted supplementary analyses on the disaggregated measures of warmth and hostility. These analyses (which are available from the authors) produced similar patterns of effects as for the combined PMEE measure but failed to reached significance overall.

\section{RESULTS:}

Among the ADHD cases, frequencies for common genotypes were similar to those found in previous studies and the data were all found to be in Hardy Weinberg Equilibrium: $(D R D 4:+7-\mathrm{N}=$ 
$232 ;-7-\mathrm{N}=452 ; D A T 1: 9 \mathrm{R} / 9 \mathrm{R}-\mathrm{N}=72 ;$ $9 \mathrm{R} / 10 \mathrm{R}-\mathrm{N}=233 ; 10 / 10-\mathrm{N}=363$. 5HTT-LPR: $\mathrm{s} / \mathrm{s}-\mathrm{N}=124$; $\mathrm{s} / \mathrm{l}-\mathrm{N}=338$; $1 / 1-N=219)$. The genotypes for the VNTRs were not significantly associated with each other $\left(\chi^{2}<5.57\right.$; ps $\left.>.2\right)$. There was no significant association between PMEE and child genotypes (DAT1 $\chi^{2}(2)=$ $0.83, p=.660$; DRD4 $\chi^{2}(1)=1.92, p=$ .166; 5HTT $\chi^{2}(2)=2.84, p=.241$ ) or maternal genotypes (DAT1 $\chi^{2}(2)=0.563$, $p=.771$; DRD4 $\chi^{2}(1)=0.32, p=.572$; 5HTT $\left.\chi^{2}(2)=0.27, p=.873\right)$. There was an effect of national centre on PMEE ( $F$ $(10,673)=3.68 ; p<0.001)$. This effect appeared to be due entirely to Spain having significantly higher levels of PMEE than the other groups (Scheffe's tests $p<0.02)$. However, national grouping did not interact with PMEE with respect to $\mathrm{CP}$ and so subject scores were pooled across national groups for the analyses. Furthermore excluding the children from the Spanish cohort had no effect on the findings.

Conduct problems: For all three genes there was a main effect of PMEE on $\mathrm{CP}$ $\left(F^{\mathrm{DRD} 4}(1,689)=10.40, p=.001 ; F^{\mathrm{DAT} 1}\right.$ $(1,608)=11.36, p=.001 ; F^{5 \mathrm{HTT}}(1,618)=$ 10.97, $p=.001)$ : Children in the high PMEE group had less CP. There was no effect of age (Fs $<.14$, ps $>.24)$ and age was not involved in any interactions with PMEE or genotype $(F \mathrm{~s}<2.20, \mathrm{p}>.130)$. For the analyses of DRD4 there was no main effect of genotype on CP levels ( $F$ $(1,625)=0.08, p=.779)$ and no genotype $\mathrm{x}$ PMEE interaction $(F(1,625)=0.13, p=$ .718). Also, no three way interaction between these factors and rater was observed $(F(1,605)=0.76, p=.383)$. Supplementary analyses found no effects for other common DRD4 genotypes (e.g., $2 \mathrm{R}$ ) or of the presence of two as opposed to just one 7R alleles. For DAT1 there was no main effect of genotype on CP levels ( $F$ $(2,608)=0.28, p=.758)$. However there was a significant interaction between genotype and PMEE $(F(2,608)=3.81, p=$ $0.023)$ which was independent of rater $(F$
$(2,588)=0.65, p=.523)$. This interaction is illustrated in figure 1a. There was a significant simple main effect of PMEE for probands with 9R/10R genotype ( $\mathrm{F}(1,213$ $=17.79 ; \mathrm{p}<0.001)$ and a trend for those with the $9 \mathrm{R} / 9 \mathrm{R}$ genotype $(\mathrm{F}(1,62)=3.39$; $p=.07)$, despite the small sample size for this group. There was no effect of PMEE for those in $10 \mathrm{R} / 10 \mathrm{R}$ group $(\mathrm{F}(1,333)=$ $0.70 ; \mathrm{p}=.404)$. From the figure it appeared that the $10 \mathrm{R} / 10 \mathrm{R}$ group were protected from the negative effects of low PMEE. However, there was no significant effect of genotype in either the high or the low PMEE groups $\left(\mathrm{F}^{\text {high }}(2,334)=1.09 ; \mathrm{p}\right.$ $\left.=.337 ; \mathrm{F}^{\text {low }}(2,280)=1.73 ; \mathrm{p}=.179\right)$.

A somewhat similar pattern of results was observed for the 5HTT gene (figure 1b). There was no main effect of genotype on $\mathrm{CP}(F(2,618)=1.55, p=.213)$ but the interaction between genotype and PMEE on risk for $\mathrm{CP}$ was significant $(\mathrm{F}(2,618)=$ $3.13, \mathrm{p}=.045)$. This again was independent of rater $(F(2,598)=0.46, p=.629)$. High PMEE conferred a protective advantage for $\mathrm{s} / \mathrm{s}$ and $\mathrm{s} / 1$ genotypes $\left(F^{\mathrm{s} / 1}(1,306)=\right.$ $12.04, p=.001 ; F^{s / s}(1,112)=6.23, p=$ $.014)$ but not $1 / 1$ genotypes $(F(1,200)=$ $0.01, p=.964)$. From figure $1 \mathrm{~b}$ it seemed that those with $1 / 1$ failed to benefit from the protective effects of PMEE. Consistent with this view there was an effect of genotype in the high PMEE environment $(F(1,356)=3.04, p=.049)$ but not the low one $(F(1,325)=1.57, p=.210)$.

Given the similarity of the findings for the 5HTT and the DAT1 groups we explored the cumulative effects of the two genes in determining sensitivity to PMEE. To do this we first identified the $1 / 1$ genotype of the 5HTT and the 10R/10R genotype of the DAT1 as those associated with insensitivity to PMEE in terms of the development of CP. We then created a genotypic index of PMEE insensitivity (GIPI) by adding these two scores: Probands with neither genotype associated with insensitivity scored ' 0 ' $(\mathrm{N}=212)$, those with one but not the other scored ' 1 ' 


\section{Figure 1a:}

The interaction between DAT1 genotypes and positive maternal expressed emotion for conduct problems

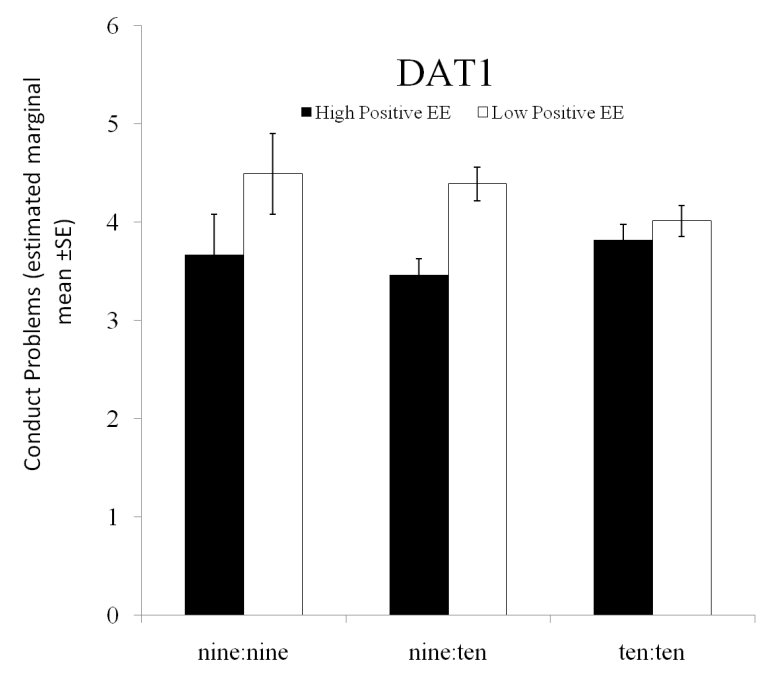

\section{Figure 1b:}

The interaction between 5HTT genotype and positive maternal expressed emotion for conduct problems

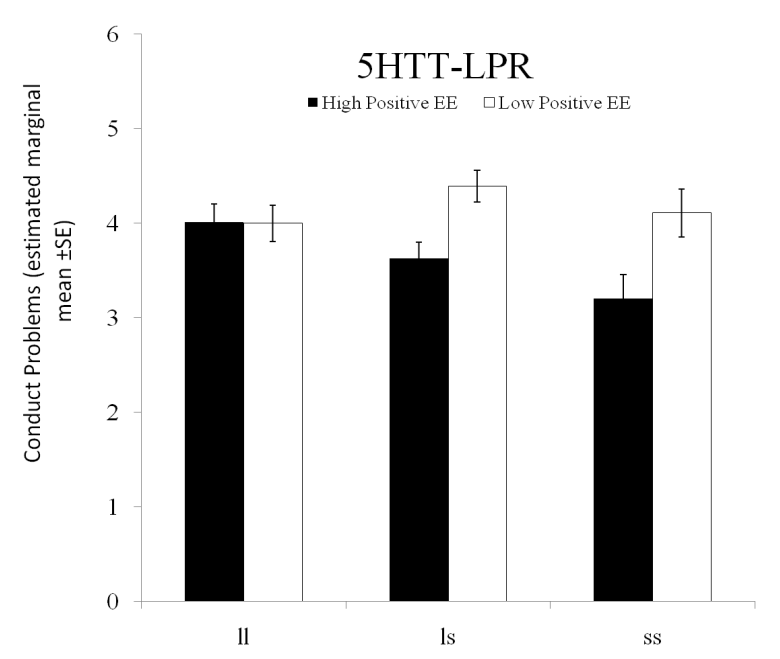

\section{Figure 1c:}

The interaction between the Genotypic Index of Environmental Insensitivity and positive maternal expressed emotion for conduct problems: This measure ranges for 0 (neither $1 / 1$ nor $10 \mathrm{R} / 10 \mathrm{R}$ ), 1 (either $1 / 1$ or $10 \mathrm{R} / 10 \mathrm{R}$ ) and 2 (both $1 / 1$ and 10R/10R).

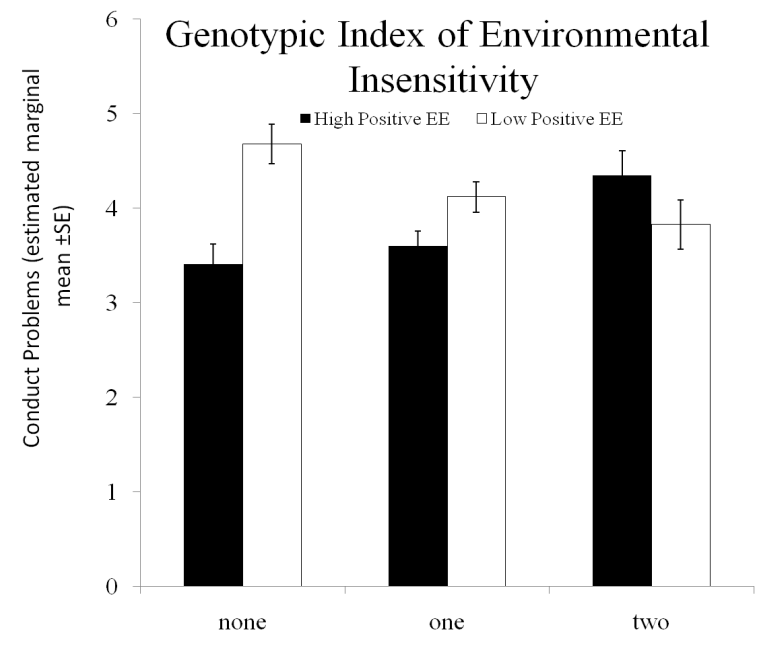

Figure 2:

The interaction between DAT1 genotypes and positive maternal expressed emotion for emotional problems

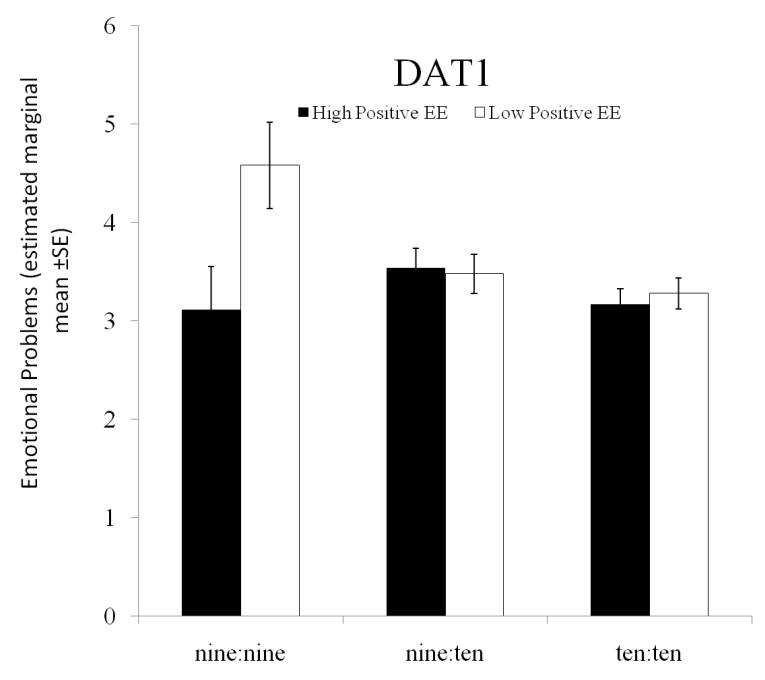


$(\mathrm{N}=343)$ and those with both scored '2' $(\mathrm{N}=118)$. We then employed this cumulative score as the independent variable in the ANOVA model described above (figure 1c). There was a main effect of $\operatorname{PMEE}(F(1,612)=5.83, p=.016)$ and a highly significant GIPI $x$ PMEE interaction $(F(2,674)=7.44, p=.001)$. This effect was independent of rater $(F$ $(2,592)=2.02, p=.133)$ and age $(F$ $(2,612)=0.87, p=.481)$. There were simple main effects of PMEE for groups with scores ' 0 ' $(\mathrm{F}(1,191)=22.06 ; \mathrm{p}<$ $0.001)$ and ' 1 ' $(\mathrm{F}(1,316)=4.97 ; \mathrm{p}=.027)$ but not a score of ' 2 ' $(\mathrm{F}(1,105)=1.95 ; \mathrm{p}=$ .166). Figure 1c suggests that compared to those with either none or one insensitivity genotypes those with both were less likely to be affected by the negative effects of low PMEE and less likely to benefit from the effects of high PMEE. This was confirmed by the finding that there was an effect of the GIPI in both the high PMEE group $(\mathrm{F}(2,333)=4.23 ; \mathrm{p}=.015)$ and the low PMEE group $(\mathrm{F}(2,279)=3.80 ; \mathrm{p}=$ .024).

Emotional Problems: When EMO was analysed as the dependent variable no effects of either PMEE (Fs < 1.35; p > $.24)$, genotype (Fs $<0.26$; p > .600) or genotype $x$ PMEE interaction (Fs < 0.94, p $>$.300) was found in the analyses for DRD4 or 5HTT-LPR genotypes. For DAT1 there was a significant effect of PMEE $(F(1,608)=5.56 ; p=.019), a$ significant trend toward a genotype effect $(\mathrm{F}(2,608)=2.98 ; \mathrm{p}=.051)$ and a significant PMEE $\mathrm{x}$ genotype interaction $(\mathrm{F}(1,608)=3.28 ; \mathrm{p}=.040)$. Figure 2 plots this interaction. There was a significant main effect of PMEE only for the 9R/9R genotype $(\mathrm{F}(1,62)=6.72 ; \mathrm{p}=.040)$. It appeared that those with the $9 \mathrm{R} / 10 \mathrm{R}$ and the $10 \mathrm{R} / 10 \mathrm{R}$ genotype were protected from the negative effects of low PMEE. This was supported by the analysis showing an effect of genotype on emotional problems for the low PMEE group $(\mathrm{F}(2,277)=3.89 ; \mathrm{p}=.022)$ but not for the high PMEE group $(\mathrm{F}(2,331)=$ $1.48 ; \mathrm{p}=.229$ ).

\section{DISCUSSION:}

Our results are consistent with a complex model of risk and resilience in the development of comorbidity in ADHD. First, they confirm an association between parenting factors, in this case PMEE, and the presence of $\mathrm{CP}$ in ADHD children. Previous data, suggest that these effects are driven, at least in part, by early appearing ADHD and associated hard-tomanage behaviour and that parental EE is in part a response to this and in part an exacerbating factor which leads to the escalation of CP (Taylor et al., 1996). Second, the association between PMEE and $\mathrm{CP}$ was significantly moderated by genetic factors. While those with the 9/9R and 9/10R of the DAT1 genotypes and the $\mathrm{s} / \mathrm{s}$ and the s/l 5HTT-LPR genotypes showed sensitivity to the effects of PMEE (the low PMEE group had more CP) those with the DAT 10R/10R or the 5HTT-LPR $1 / 1$ genotypes did not. While the size of these interaction effects were small individually, the effects were much greater when the genotypes associated with insensitivity to PMEE were added together to create a cumulative index. Importantly these effects were independent of whether a parent or a teacher was rating the child's behaviour, did not vary significantly across national setting and appeared similar in childhood and adolescence (i.e., there was no effect of age category). As predicted there was no main effect of PMEE on EMO in the current sample. However, there was a gene $\mathrm{x}$ environment interaction for DAT1 with an effect being found for those children with the 9R/9R genotype, as was seen for $\mathrm{CP}$, but no effect at all for those with 9R/10R (differing from that seen for CP) and the 10R/10R genotypes. In supplementary analysis we also looked at the impact of maternal warmth and criticism separately and found that while the pattern of effects was similar for these two components of EE, the disaggregated 
Table 1: The SDQ conduct and emotional scores for DAT1, DRD4 and 5HTT-LPR genotypes as a function of level of positive maternal expressed emotion. (PMEE).

\begin{tabular}{|c|c|c|c|c|c|c|c|c|}
\hline & \multicolumn{4}{|c|}{ Conduct Problems } & \multicolumn{4}{|c|}{ Emotional Problems } \\
\hline & \multicolumn{2}{|c|}{ High PMEE } & \multicolumn{2}{|c|}{ Low PMEE } & \multicolumn{2}{|c|}{ High PMEE } & \multicolumn{2}{|c|}{ Low PMEE } \\
\hline & $\mathbf{P}$ & $\mathbf{T}$ & $\mathbf{P}$ & $\mathbf{T}$ & $\mathbf{P}$ & $\mathbf{T}$ & $\mathbf{P}$ & $\mathbf{T}$ \\
\hline DAT1 & & & & & & & & \\
\hline 9R/9R & 4.29 & 3.09 & 5.52 & 3.07 & 3.26 & 3.06 & 4.42 & 3.57 \\
\hline $\mathrm{N}=72$ & \pm 2.3 & \pm 2.1 & \pm 2.0 & \pm 2.1 & \pm 2.3 & \pm 2.7 & \pm 3.0 & \pm 2.6 \\
\hline 9R/10R & 4.07 & 2.83 & 5.56 & 3.32 & 3.81 & 3.32 & 4.24 & 2.74 \\
\hline $\mathrm{N}=233$ & \pm 2.2 & \pm 2.3 & \pm 2.5 & \pm 2.3 & \pm 2.5 & \pm 2.4 & \pm 2.6 & \pm 2.5 \\
\hline $10 \mathrm{R} / 10 \mathrm{R}$ & 4.35 & 3.23 & 4.87 & 3.09 & 3.58 & 2.71 & 3.88 & 2.63 \\
\hline $\mathrm{N}=363$ & \pm 2.3 & \pm 2.5 & \pm 2.2 & \pm 2.3 & \pm 2.5 & \pm 2.2 & \pm 2.4 & \pm 2.2 \\
\hline DRD4 & & & & & & & & \\
\hline$-7 R$ & 4.26 & 3.00 & 5.16 & 3.24 & 3.60 & 2.87 & 4.13 & 2.91 \\
\hline $\mathrm{N}=233$ & \pm 2.2 & \pm 2.3 & \pm 2.3 & \pm 2.3 & \pm 2.5 & \pm 2.3 & \pm 2.5 & \pm 2.3 \\
\hline$+7 \mathrm{R}$ & 4.22 & 3.16 & 5.22 & 2.95 & 3.67 & 3.07 & 4.06 & 2.50 \\
\hline $\mathrm{N}=452$ & \pm 2.3 & \pm 2.5 & \pm 2.1 & \pm 2.3 & \pm 2.4 & \pm 2.3 & \pm 2.6 & \pm 2.3 \\
\hline 5HTT & & & & & & & & \\
\hline $\mathrm{s} / \mathrm{s}$ & 3.72 & 2.76 & 5.12 & 3.07 & 3.48 & 3.12 & 4.05 & 2.73 \\
\hline $\mathrm{N}=124$ & \pm 2.2 & \pm 2.4 & \pm 2.1 & \pm 2.4 & \pm 2.6 & \pm 2.0 & \pm 2.7 & \pm 2.3 \\
\hline $\mathrm{s} / \mathrm{l}$ & 4.18 & 3.06 & 5.37 & 3.30 & 3.59 & 3.07 & 3.92 & 2.68 \\
\hline $\mathrm{N}=338$ & \pm 2.2 & \pm 2.2 & \pm 2.3 & \pm 2.3 & \pm 2.4 & \pm 2.3 & \pm 2.5 & \pm 2.5 \\
\hline $1 / 1$ & 4.66 & 3.29 & 4.91 & 3.00 & 3.68 & 2.62 & 4.34 & 2.94 \\
\hline $\mathrm{N}=219$ & \pm 2.3 & \pm 2.6 & \pm 2.3 & \pm 2.3 & \pm 2.5 & \pm 2.5 & \pm 2.6 & \pm 2.2 \\
\hline
\end{tabular}

Note: $\mathrm{P}=$ parent SDQ; $\mathrm{T}=$ teacher SDQ 
measures were far less powerful at predicting the presence of comorbidity than was the combined measure - a finding which appears to support the value of the broader construct of EE as a combination of warmth and criticism.

There are in principal a number of possible ways to interpret the reduced sensitivity to PMEE seen for the $1 / 1$ and the $10 \mathrm{R} / 10 \mathrm{R}$ genotypes (and the $9 \mathrm{R} / 10 \mathrm{R}$ for EMO). First, there could be a protective effect of the genotype in terms of reducing the negative effects of parental hostility and lack of warmth. Second, there could be a risk element associated with the genotype expressed as a reduction of the positive effect of high PMEE. Third, it could be that the genotype produces a more general insensitivity to environmental factors, whether they have positive or negative effects in those without the genotype. The current results are rather mixed in this regard. For DAT1 the data favour this latter sort of explanation with those with 10R/10R having lower $\mathrm{CP}$ under the low PMEE condition than those patients with $9 \mathrm{R} / 9 \mathrm{R}$ and 10R/9R genotypes and higher levels of $\mathrm{CP}$ than these under high PMEE. For 5HTT-LPR it seemed that those with $1 / 1$ genotype failed to benefit from the high PMEE as those patients with the other genotype did. The overall pattern of results for the cumulative index also support a general insensitivity hypothesis with those with both 'insensitivity' genotypes showing less CP under the low PMEE and more $\mathrm{CP}$ under the high PMEE than those with either one or no insensitivity genotypes. The data for EMO and DAT1 provides evidence for the protective value of the $9 R / 10 R$ and the $10 R / 10 R$ genotype in the current study.

This pattern of findings for the two significant genotypes and for their aggregation is rather different to the pattern seen in previous studies. Those studies typically reported a synergistic interplay between genetic and environ- mental factors in the development of disorder (Rutter, Moffitt \& Caspi, 2006), where children carrying a particular genotype are at increased risk for disorder when exposed to a particular environmental risk (Caspi et al., 2003). That is, the environmental effect is manifest for those with one but not another type of genotype. This was not the case in the current paper where the presence of different genotypes led to opposite effects depending on the operating environmental conditions, vis-vis risk - in high risk settings (e.g., low PMEE) one genotype may play protective effect while under low risk or positive settings it produced a negative or an antagonistic effect (Ottman, 1996). The most parsimonious explanation may be that certain genotypes simply reduce (and others increase) the sensitivity to environmental effects in a general way. Distinguishing such insensitivity genotypes from genotypes with more specific risk and protective properties seems an important goal for future research (Belsky, Bakermans-Kranenburg \& van IJzendoorn, 2007).

Generally there are a number of plausible biological and psychological mechanisms that might account for these sorts of gene by environment effects. For example genetic factors may 'block' the exposure of children to, or determine their degree of sensitivity to, the beneficial effects of positive parenting or the harmful effects of parental dysfunction. Genetic factors may reduce the receptivity of children to the experience of maternal warmth and criticism or the impact that this has on their difficult and challenging behaviour. Alternatively genetic factors may alter the extent to which attitudes and emotions, expressed about the child in an interview setting, actually result in parenting behaviour (be it positive or negative) is expressed toward the child. Observation of mother-child interaction would be necessary to test these two hypotheses. 
A second class of explanations focuses more on the possibility that high or lowrisk environments (such as that characterised by low and high PMEE respectively) alter the expression or effect of genes. First, risk environments may have powerful effects that may 'swamp' smaller and less robust genetic effects. This may be a problem especially for polygenic disorders (such as ADHD and $\mathrm{CP}$ ) where effects are determined by many genes of small effect acting together. On the other hand, a more biologically interesting possibility derives from the hypothesis that adverse social environments may 'switch-off', or socially benign environments 'switch-on' genetic effects through epigenetic mechanisms such as DNA methylation (Mill \& Petronis, 2008). While almost nothing is known empirically about the power of the family environment to impinge on gene expression within the human infant, recent animal models suggest that such effects are plausible (Parent et al., 2005; Diorio \& Meany, 2007).

Previous research has implicated the 5HTT gene in both externalising (i.e., aggression; Haberstick, Smolen \& Hewitt, 2006) and internalising problems (i.e., depression; Eley et al., 2004) and pointed to it as one of the best examples to date of a genetic moderator of environmental adversity (Caspi et al., 2003; Kendler et al., 2005). In contrast to most previous research, in the current study the $1 / 1$ genotype rather than the s/s genotype was associated with greater risk for $\mathrm{CP}$ in the low risk environmental setting (Kendler et al., 2005), although as discussed above the 1 allele has been associated with risk for ADHD (see also Nobile et al., 2007). Furthermore, surprisingly, given the extensive literature linking 5HTT-LPR to depression (Eley et al., 2004), the effects found for CP with this gene in the current study did not extend to EMO. It should also be born in mind that the SDQ EMO phenotype in the current study neither specifically probed depression nor allowed a clinical diagnosis (Goodman et al., 2000). The presence of the 5HTT-LPR genotype was especially potent when it was accompanied by the DAT1 10/10 genotype suggestive of synergies between serotonin and dopamine systems (Oades, 2002) consistent with the recent paper by Schmidt and colleagues (Schmidt, Fox \& Hamer, 2007).

Consistent with the current findings previous studies have implicated DAT1 in the aetiology of CP. However, there have been inconsistencies regarding the identity of the risk genotype with a number of studies implicating the $9 \mathrm{R}$ allele rather than the $10 \mathrm{R}$ allele as most significant (Lee et al., 2007; Young et al., 2002). However, Guo et al. (2007) recently found evidence for a significantly increased risk for $\mathrm{CP}$ associated with the presence of at least one 10R allele. The current study supports the significance of the $10 \mathrm{R} / 10 \mathrm{R}$ as operating in a different way from the other common genotypes - although it would not be accurate to describe it as a risk genotype for $\mathrm{CP}$ as it did not significantly increase risk of disorder in the low risk environment. In all these studies it is unclear how specific these effects are to $\mathrm{CP}$ rather than ADHD. What is distinctive in the current study is that levels of ADHD are constant in the sample, which suggests a specific role in relation to $\mathrm{CP}$ in addition to any role in ADHD? The finding showing that the 9R/9R allele can increase risk of EMO in the high risk setting provides the first evidence linking this gene to emotional problems. Further research with more refined and clinically informative EMO phenotypes is required. Although studies have previously demonstrated a possible role for DRD4 in moderating the effects of the child's early social environment this was not the case here. However, PMEE, the construct employed in the current study, is not directly related to those employed in previous studies (i.e., maternal insensitivity; BakermansKranenburg \& van IJzendoorn, 2006). 
Our study had a number of limitations: First, the study was limited to male participants with combined type ADHD and mothers PMEE. A comparison of the effects of maternal and paternal EE in the IMAGE study suggested that there may be different effects by gender for parental EE and these may also be affected by the gender of the proband (Psychogiou et al., submitted). Second, the participants in the IMAGE study are all patients and a significant number were, or had in the past, received medication for their condition. There are potentially important implications of this. First, treatment may alter the relationship between PMEE and conduct and emotional problems in the sample and also the extent to which these are moderated by genetic factors. Second, assessments of $\mathrm{EE}$ and the presence of conduct and emotional problems may be biased if they are based on observations made during periods when participants were receiving medication. Because systematic data on medication history was not available, an analysis of the association between medication history and the effects of PMEE on conduct and emotional problems was not possible. We did attempt to limit the potential biasing effects of assessment based on periods of active medication by limiting the current analysis only to those whose EE and psychopathology evaluation was made on the basis of current or recent medication free periods. Ideally the current analyses would be repeated in a medication-naive group - unfortunately this was not feasible in the current study given the need for the very large numbers of probands required to test for gene by environment effects. Third, despite the fact that these effects were independent of whether data about $\mathrm{CP}$ and EMO was derived from teachers or parents, there remained a possibility of shared-method variance. In future analyses it would be good if the assessment of EE toward the patient was based on both the mother's responses during an interview and on direct observation of actual behaviour during mother-child interaction. Fourth, the effects of only three genes were assessed. While this is a strength, as the selection of genes was based on hypothesis rather than a data trawl, quite clearly there may be many other genes implicated in the relation between $\mathrm{CP}$ and ADHD. MAOA and COMT are obvious examples but these had not been genotyped for the whole IMAGE sample at the time of the analyses in this paper. Finally, this was a cross-sectional study and therefore the causal relationship between EE and CP and EMO would need to be established in a longitudinal followup of the current sample.

In summary, the current results demonstrated a role for gene $\mathrm{x}$ family environment interaction in determining the presence of $\mathrm{CP}$ (and to a lesser extent EMO) in ADHD children in a very large nationally diverse cohort of ADHD patients (both children and adolescents). 5HTT and DAT1 genotypes appeared to moderate the impact of PMEE by reducing both the negative effects of low PMEE and the positive effects of high PMEE perhaps by promoting a generalised insensitivity to this particular environmental factor. $\mathrm{CP}$ and EMO is a major source of clinical impairment in ADHD and is an important target for both scientific study and clinical intervention. We have known for some time that variations in the quality of family environments may be implicated in the aetiology of these comorbidities (Taylor et al., 1996). The current results refine this understanding by illustrating the possibility that the genetic make-up of an individual may alter the degree to which a person is sensitive to their environment. 


\section{References}

Achenbach, T., Becker, A., Döpfner, M., Heiervang, E., Roessner, V., Steinhausen, H.C., \& Rothenberger, A. (2008). Multicultural Assessment of Child and Adolescent Psychopathology with ASEBA and SDQ Instruments: Research Findings, Applications, and Future Directions. Journal of Child and Adolescent Psychiatry, 49, 251-275.

Altkin, M. E., Arias-Vasquez, A., Franke, B., et al. (2008). The dopamine receptor D4 7-repeat allele and prenatal smoking in ADHD affected children and their unaffected siblings: no geneenvironment interaction. The Journal of Child Psychology and Psychiatry, 49, 1053-1060.

Asherson, P., Brookes, K., Franke, B., et al. (2007). Confirmation that a specific haplotype of the dopamine transporter gene is associated with combined-type ADHD. American Journal of Psychiatry, 164, 674-677.

Baker, B., Heller, T., \& Henker, B. (2000). Expressed emotion, parenting stress, and adjustment in mothers of young children with behaviour problems. Journal of Child Psychology and Psychiatry, 41, 907-915.

Bakermans-Kranenburg, M.J., \& van IJzendoorn, M.H. (2006). Geneenvironment interaction of the dopamine D4 receptor (DRD4) and observed maternal insensitivity predicting externalizing behavior in preschoolers Developmental Psychobiology, 48, 406-409.

Becker, K., El-Faddagh, M., Schmidt, M.H., Esser, G., \& Laucht, M. (2008). Interaction of dopamine transporter genotype with prenatal smoke exposure on ADHD symptoms. Journal of Pediatrics, 152, 263-269.

Belsky, J., Bakermans-Kranenburg, M. J., \& van IJzendoorn, M. H. (2007). For better and for worse: Differential susceptibility to environmental influences. Current Directions in Psychological Science, 16, 300-304.

Biederman, J. (2005). AttentionDeficit/Hyperactivity Disorder: A selective overview. Biological Psychiatry, 57, 1215-1220.

Brookes, K., Xu, X., Chen, W., et al. (2006a). The analysis of 51 genes in DSM-IV combined type attention deficit hyperactivity disorder: association signals in DRD4, DAT1 and 16 other genes. Molecular Psychiatry, 11, 934-53.

Brookes, K.J., Mill, J., Guindalini, C., et al. (2006b). A common haplotype of the dopamine transporter gene associated with attention-deficit/hyperactivity disorder and interacting with maternal use of alcohol during pregnancy. Archives of General Psychiatry, 63, 7481.

Brookes, K.J., Neale. B., Thapar, A., et al. (2008). Differential Dopamine Receptor D4 Allele Association with ADHD Dependent on Proband Season of Birth. American Journal of Medical Genetics Part B: Neuropsychiatric Genetics, 147B, 94-99.

Caspi, A., Langley, K., Milne, B., et al. (2008). A replicated molecular genetic basis for sub-typing antisocial behavior in children with attentiondeficit/hyperactivity disorder. Archives of General Psychiatry, 65, 203-210.

Caspi, A., Sugden, K., Moffitt, T.E., et al. (2003). Influence of life stress on depression: moderation by a polymorphism in the 5-HTT gene. Science, 301, 386-389.

Chen, W., \& Taylor, E. (2006). PACS interview and genetic research of ADHD. In R. Oades (Ed.), Attention Deficit/Hyperactivity Disorder HKS: 
Current ideas and ways forward (pp. 320). New York: Nova Science Publishers.

Cicchetti, D., Rogosch, F.A., \& SturgeApple, M.L. (2007). Interactions of child maltreatment and serotonin transporter and monoamine oxidase $A$ polymorphisms: Depressive symptomatology among adolescents from low socioeconomic status backgrounds. Developmental Psychopathology, 19, 1161-1180.

Conners, C. (2003). Conners' Rating Scales-Revised: Technical Manual. 6th Printing, MHS.

Daley, D., Sonuga-Barke, E., \& Thompson, M. (2003). Assessing expressed emotion in mothers of preschool AD/HD children: Psychometric properties of a modified speech sample. British Journal of Clinical Psychology, 42, 53-67.

Diorio, J., \& Meaney, M.J. (2007). Maternal programming of defensive responses through sustained effects on gene expression. Journal of Psychiatric Neuroscience, 32, 275-284.

Eley, T.C., Sugden, K., Corsico, A., Gregory, A.M., Sham, P., McGuffin, P., Plomin, R., \& Craig, I.W. (2004). Geneenvironment interaction analysis of serotonin system markers with adolescent depression. Molecular Psychiatry, 9, 908-915.

Faraone, S.V., Perlis, R.H., Doyle, A.E., Smoller, J.W., Goralnick, J.J., Holmgren, M.A., \& Sklar, P. (2005). Molecular genetics of attentiondeficit/hyperactivity disorder. Biological Psychiatry, 57, 1313-1323.

Gerra, G., Zaimovic, A., Garofano, L., et al.(2007). Perceived parenting behavior in the childhood of cocaine users: Relationship with genotype and personality traits. American Journal of Medical Genetics Part B, 144B, 52-57.

Goodman, R. (1997). The strengths and difficulties questionnaire: a research note. Journal of Child Psychology and Psychiatry, 38, 581-586.

Goodman, R., Ford, T., Simmons, H., Gatward, R., \& Meltzer, H. (2000). Using the Strengths and Difficulties Questionnaire (SDQ) to screen for child psychiatric disorders in a community sample. British Journal of Psychiatry, 177, 534-539.

Guo, G., Roettger, M.E., \& Shih, J.C. (2007). Contributions of the DAT1 and DRD2 genes to serious and violent delinquency among adolescents and young adults. Human Genetics, 121, 125-136.

Haberstick, B.C., Smolen, A., \& Hewitt, J.K. (2006). Family-based association test of the 5HTTLPR and aggressive behavior in a general population sample of children. Biological Psychiatry, 59, 836-843.

Hinshaw, S.P. (1992). Academic underachievement, attention deficits, and aggression: Comorbidity and implications for interventions. Journal of Consulting and Clinical Psychology, 60, 893-90.

Jensen, P. S., Hinshaw, S. P., Kraemer, H. C., Lenora, N., Newcorn, J. H., Abikoff, H. B., et al. (2001). ADHD comorbidity findings from the MTA study: Comparing comorbid subgroups. Journal of the American Academy of Child and Adolescent Psychiatry, 40, 147-158.

Johnston, C., \& Mash, E. (2001). Families of children with attention deficit/hyperactivity disorder: Review and recommendations for future research. Clinical Child and Family Psychology Review, 4, 183207.

Kahn, R.S., Khoury, J., Nichols, W.C., \& Lanphear, B.P. (2003). Role of dopamine transporter genotype and 
maternal prenatal smoking in childhood hyperactive-impulsive, inattentive, and oppositional behaviors. Journal of Pediatrics, 143, 104-10.

Kendler, K.S., Kuhn, J.W., Vittum, J., Prescott, C.A., \& Riley, B. (2005). The interaction of stressful life events and a serotonin transporter polymorphism in the prediction of episodes of major depression - A replication. Archives of General Psychiatry, 62, 529-535.

Kepley, H., \& Ostrander, R. (2007). Family characteristics of anxious ADHD children. Preliminary results. Journal of Attention Disorders, 10, 317-323.

Kent, L., Doerry, U., Hardy, E., et al. (2002). Evidence that variation at the serotonin transporter gene influences susceptibility to attention deficit hyperactivity disorder (ADHD): Analysis and pooled analysis. Molecular Psychiatry, 7, 908-912.

Kim, J., Kim B., \& Cho, S. (2006). The dopamine transporter gene and the impulsivity phenotype in attention deficit hyperactivity disorder: A casecontrol association study in a Korean sample. Journal of Psychiatric Research, 40, 730-737.

Kim-Cohen, J., Caspi, A., Taylor, A., et al. (2006). MAOA, maltreatment, and gene-environment interaction predicting children's mental health: new evidence and a meta-analysis. Molecular Psychiatry, 11, 903-913.

Lahey, B., McBurnett, K., \& Loeber R (2000). Are attention-deficit/ hyperactivity disorder and oppositional defiant disorder developmental precursors to conduct disorder? In A. Sameroff, M. Lewis, S. Miller (Eds.), Handbook of developmental psychology 2nd Edn. (pp. 431-446). New York: Plenum Press.

Lasky-Su, J., Banaschewski, T., Buitelaar, J., et al. (2007). Partial replication of a
DRD4 association in ADHD individuals using a statistically derived quantitative trait for ADHD in a family-based association test. Biological Psychiatry, 62, 985-990.

Laucht, M., Skowronek, M.H., Becker, K., Schmidt, M.H., Esser, G., Schulze, T.G., \& Rietschel, M. (2007). Interacting effects of the dopamine transporter gene and psychosocial adversity on attention-deficit/hyperactivity

disorder symptoms among 15-yearolds from a high-risk community sample. Archives of General Psychiatry, 64, 585-590.

Lee, S.S., Lahey, B.B., Waldman, I., Van Hulle, C.A., Rathouz, P., Pelham, W.E., Loney, J., \& Cook, E.H. (2007). Association of dopamine transporter genotype with disruptive behavior disorders in an eight-year longitudinal study of children and adolescents. American Journal of Medical Genetics Part B, 144B, 310-317.

Li, D.W., Sham, P.C., Owen, M.J., \& He, L. (2006). Meta-analysis shows significant association between dopamine system genes and attention deficit hyperactivity disorder (ADHD). Human Molecular Genetics, 15, 22762284.

Li, J., Wang, Y.F., Zhou, R.L., Zhang, H.B., Yang, L., Wang, B., \& Faraone, S.V. (2007). Association between polymorphisms in serotonin transporter gene and attention deficit hyperactivity disorder in Chinese Han subjects. American Journal of Medical Genetics Part B, 144B, 14-19.

Lynam, D.R. (1996). Early identification of chronic offenders: who is the fledging psychopath? Psychological Bulletin, 120, 209-234.

Mill, J., \& Petronis, A. (2008). Pre- and perinatal environmental risks for attention-deficit hyperactivity disorder (ADHD): the potential role of 
epigenetic processes in mediating susceptibility. Journal of Child Psychology and Psychiatry, 49, 10201030.

Neuman, R.J., Lobos, E., Reich, W., Henderson, C.A., Sun, L.W., \& Todd, R.D. (2007). Prenatal smoking exposure and dopaminergic genotypes interact to cause a severe ADHD subtype. Biological Psychiatry, 61, 1320-1328.

Nobile, M., Giorda, R., Marino, C., Carlet, O., Pastore, V., Vanzin, L., Bellina, M., Molteni, M., \& Battaglia, M. (2007). Socioeconomic status mediates the genetic contribution of the dopamine receptor D4 and serotonin transporter linked promoter region repeat polymorphisms to externalization in preadolescence. Developmental Psychopathology, 19, 1147-1160.

Oades, R.D. (2002). Dopamine may be 'hyper' with respect to noradrenaline metabolism, but 'hypo' with respect to serotonin metabolism in children with attention-deficit hyperactivity disorder Behavioral Brain Research, 130, 97102.

Ostrander, R., \& Herman, K. (2006).Potential cognitive, parenting, and developmental mediators of the relationship between ADHD and depression. Journal of Consulting and Clinical Psychology, 74, 89-98.

Ottman, R. (1996). Gene-Environment Interaction: Definitions and Study Designs. Preventive Medicine, 25, 764770.

Parent, C., Zhang, T.Y., Caldji, C., Bagot, R., Champagne, F.A., Pruessner, J., \& Meaney, M.J. (2005). Maternal care and individual differences in defensive responses. Current Directions in Psychological Science, 14, 229-233.

Patterson, G. (1982). Coercive family process. Eugene, OR: Castalia.
Peedicayil, J. (2007). The role of epigenetics in mental disorders. Indian Journal of Medical Research, 126, 105111.

Pfiffner, L., \& McBurnett, K. (2006). Family correlates of comorbid anxiety disorders in children with attention deficit/hyperactivity disorder. Journal of Abnormal Child Psychology, 34, 725735.

Pfiffner, L., Mcburnett, K., Rathouz, P., \& Judice, S. (2005). Family Correlates of Oppositional and Conduct Disorders in Children with Attention Deficit/ Hyperactivity. Journal of Abnormal Child Psychology, 33, 551-563.

Propper, C., Willoughby, M., Halpern, C.T., Carbone, M.A., \& Cox, M. (2007). Parenting quality, DRD4, and the prediction of externalizing and internalizing Behaviors in early childhood. Developmental Psychobiology, 49, 619-632.

Psychogiou, L., Daley, D., Thompson, M., \& Sonuga-Barke, E. (2007). Mothers' Expressed Emotion toward their school-aged sons: Associations with child and maternal symptoms of psychopathology, European Child and Adolescent Psychiatry, 16, 458-464.

Psychogiou, L., Thompson, M., Christiansen, H., et al. (submitted). Parental expressed emotion and comorbid disorders in children with ADHD: Effects by parent gender European Child and Adolescent Psychiatry.

Reif, A., Rosler, M., Freitag, C.M., et al., (2007). Nature and nurture predispose to violent behavior: Serotonergic genes and adverse childhood environment. Neuropsychopharmacology, 32, 2375-2383.

Rutter, M., Moffitt, T.E., \& Caspi, A. (2006). Gene-environment interplay and psychopathology: multiple varieties but real effects. Journal of 
Child Psychology and Psychiatry, 47, 226-261.

Sakai, J.T., Lessem, J.M., Haberstick, B.C., Hopfer, C.J., Smolen, A., Ehringer, M.A., Timberlake, D., \& Hewitt, J.K. (2007). Case-control and within-family tests for association between 5HTTLPR and conduct problems in $a$ longitudinal adolescent sample. Psychiatric Genetics, 17, 207-214.

Schachar, R., \& Tannock, R. (1995). Test of four hypotheses for the comorbidity of attention-deficit hyperactivity disorder and conduct disorder. Journal of the American Academy of Child \& Adolescent Psychiatry, 34, 639-648.

Schachar, R., Taylor, E., Wieselberg, M., Thorley, G., \& Rutter, M. (1987). Changes in family function and relationships in children who respond to methylphenidate. Journal of the American Academy of Child \& Adolescent Psychiatry, 26, 728-732.

Schmidt, L.A., Fox, N.A., \& Hamer, D.H. (2007). Evidence for a gene-gene interaction in predicting children's behavior problems: Association of serotonin transporter short and dopamine receptor D4 long genotypes with internalizing and externalizing behaviors in typically developing 7year-olds. Developmental Psychopathology, 19, 1105-1116.

Sonuga-Barke, E. J. S., Buitelaar, J., Bitsakou, P., et al. (2008a). Intelligence in DSM-IV Combined Type AttentionDeficit/Hyperactivity Disorder is not predicted by either Dopamine Receptor/Transporter Genes or other previously identified Risk Alleles for Attention-Deficit/Hyperactivity

Disorder. American Journal of Medical Genetics Part B Neuropsychiatric Genetics, 147B, 316-319.

Sonuga-Barke, E. J. S., Lasky-Su, J., Neale, B. M., et al. (2008b). Does parental expressed emotion moderate genetic effects in ADHD? An exploration using a genome wide association scan. American Journal of Medical Genetics, 147B, 1359-1368.

Stubbe, D., Zahner, G., Goldstein, M., \& Leckman, J. (1993). Diagnostic specificity of a brief measure of expressed emotion: A community study of children. Journal of Child Psychology and Psychiatry, 34, 139154.

Tannock, R. (2000). Attention-deficit/ hyperactivity disorder with anxiety disorders. In T. E. Brown (ed.), Attention-deficit disorders and comorbidities in children, adolescents, and adults (pp. 125-170). Washington DC: American Psychiatric Press.

Taylor, E., Chadwick, O., Heptinstall, E., \& Danckaerts, M. (1996). Hyperactivity and conduct problems as risk factors for adolescence development. Journal of the American Academy of Child \& Adolescent Psychiatry 35, 1312-1226.

Taylor, E., Sandberg, S., Thorley, G., \& Giles, S. (1991). The epidemiology of childhood hyperactivity. Oxford, England: Oxford University Press.

Thapar, A., Langley, K., Asherson, P., \& Gill, M. (2007). Gene-environment interplay in attention-deficit hyperactivity disorder and the importance of a developmental perspective. British Journal of Psychiatry, 190, 1-3.

Vostanis, P., Nicholls, J., \& Harrington, R. (1994). Maternal expressed emotion in conduct and emotional disorders of childhood. Journal of Child Psychology and Psychiatry, 35, 365-376.

Yang, B., Chan, R. C., Jing, J., Li, T., Sham, P. \& Chen, R. Y. (2007). A metaanalysis of association studies between the 10-repeat allele of a VNTR polymorphism in the 3'-UTR of dopamine transporter gene and attention deficit hyperactivity 
disorder. American Journal of Medical

Genetics Part B Neuropsychiatric Genetics, 144B, 541-550.

Young, S.E., Smolen, A., Corley, R.P., Krauter, K.S., DeFries, J.C., Crowley, T.J., \& Hewitt, J.K. (2002). Dopamine transporter polymorphism associated with externalizing behavior problems in children. American Journal of Medical Genetics, 114, 144-149.

Xu, X., Aysimi, E., Anney, R., et al. (2008). No Association between two Polymorphisms of the Serotonin Transporter Gene and Combined Type Attention Deficit Hyperactivity Disorder. American Journal of Medical
Genetics Part B: Neuropsychiatric Genetics, 147(B)(7),1306-1309.

Zhou, K., Chen, W., Buitelaar, T., et al. (2008). Genetic Heterogeneity in ADHD: DAT1 Gene Only Affects Probands without CD. American Journal of Medical Genetics Part B: Neuropsychiatric Genetics, 147B, 1481-1487.

\section{Acknowledgements}

The IMAGE project is a multi-site, international effort supported by NIH grant R01MH62873 to S.V. Faraone. Site Principal Investigators are Philip Asherson, Tobias Banaschewski, Jan Buitelaar, Richard P. Ebstein, Stephen V. Faraone, Michael Gill, Ana Miranda, Robert D. Oades, Herbert Roeyers, Aribert Rothenberger, Joseph Sergeant, Edmund Sonuga-Barke, and Hans-Christoph Steinhausen; senior coinvestigators are Ian Craig, Peter McGuffin, Robert Plomin, Pak Sham, Eric Taylor, Iris Manor, Jacques Eisenberg and Margaret Thompson. Chief Investigators are Evi Bitsakou, Marieke Altink, Wai Chen, Hanna Christiansen, Barbara Franke, Rafaela Marco, U Mueller, Fernando Mulas, Lamprini Psychogiou, Nanda Rommelse, Aisling Mulligan and Henrik Uebel. Other investigators are Cathelijne Buschgens, Frits Boer, Alysa Doyle, Ellen Fliers, Alexander Heise and Ruud Minderaa. We thank all the families who kindly participated in this research. We thank Keeley Brookes and Xiao Xu for genotyping. 